\title{
Delayed chronic intracranial subdural hematoma complicating resection of a tanycytic thoracic ependymoma
}

\author{
Rosario Maugeri, Antonella Giugno, Francesca Graziano, Massimiliano Visocchi ${ }^{1}$, Cole Giller ${ }^{2}$, \\ Domenico Gerardo Iacopino
}

\begin{abstract}
Department of Experimental Biomedicine and Clinical Neuroscience, Neurosurgical Unit, Paolo Giaccone University Hospital, Palermo, Italy, ${ }^{1}$ Neurosurgical Unit Clinic, Catholic University, Rome, Italy, ${ }^{2}$ Neurosurgical Unit, Medical College of Georgia Hospital, Augusta, GA, USA

E-mail: Rosario Maugeri - rosario.maugeri1977@gmail.com; Antonella Giugno - alfagamma82@libero.it;

Francesca Graziano - franeurosurgery@libero.it; Massimiliano Visocchi - mvisocchi@hotmail.com; Cole Giller - cole.giller@comcast.net;

*Domenico Gerardo Iacopino - gerardo.iacopino@unipa.it

*Corresponding author
\end{abstract}

Received: 21 August $15 \quad$ Accepted: 17 October $15 \quad$ Published: 07 January 16

\begin{abstract}
Background: To demonstrate that the diagnosis of an intracranial subdural hematoma should be considered for patients presenting with acute or delayed symptoms of intracranial pathology following resection of a spinal tumor.

Case Description: We present a case of a 57-year-old woman found to have a chronic subdural hematoma 1 month following resection of a thoracic extramedullary ependymoma. Evacuation of the hematoma through a burr hole relieved the presenting symptoms and signs. Resolution of the hematoma was confirmed with a computed tomography (CT) scan.

Conclusion: Headache and other symptoms not referable to spinal pathology should be regarded as a warning sign of an intracranial subdural hematoma, and a CT scan of the head should be obtained. The mechanism of the development of the hematoma may be related to the leakage of cerebrospinal fluid with subsequent intracranial hypotension leading to an expanding subdural space and hemorrhage.

Key Words: Cerebrospinal fluid leakage, chronic subdural hematoma, thoracic ependymoma

\begin{tabular}{l}
\hline Access this article online \\
\hline Website: \\
www.surgicalneurologyint.com \\
\hline DOI: \\
10.4103/2152-7806.173563 \\
\hline Quick Response Code: \\
\hline
\end{tabular}
\end{abstract}

\section{BACKGROUND}

Chronic subdural hematoma is a common condition occurring typically in the elderly after a mild head injury. ${ }^{[8]}$ The mechanism is thought to involve a series of small hemorrhages into the subdural space, perhaps exacerbated by tears in the arachnoid that allow ingress of cerebrospinal fluid (CSF) and blood. ${ }^{[5]}$ Less frequently, chronic subdural hematomas may result from procedures such as lumbar puncture or myelography, which can produce intracranial hypotension due to the release of CSF. The subsequent downward shift of the brain enlarges the subdural space and stretches the small bridging veins, leading to the hematoma by mechanisms similar to these described above. ${ }^{[2,10]}$
Although dural tears occurring during resection of spinal tumors are relatively common, symptomatic intracranial hypotension resulting from CSF loss in this setting is rare. The development of a chronic subdural hematoma after such a dural tear is even more rare and has been

This is an open access article distributed under the terms of the Creative Commons Attribution-NonCommercial-ShareAlike 3.0 License, which allows others to remix, tweak, and build upon the work non-commercially, as long as the author is credited and the new creations are licensed under the identical terms.

For reprints contact: reprints@medknow.com

How to cite this article: Maugeri R, Giugno A, Graziano F, Visocchi M, Giller C, lacopino DG. Delayed chronic intracranial subdural hematoma complicating resection of a tanycytic thoracic ependymoma. Surg Neurol Int 2016;7:S20-2.

http://surgicalneurologyint.com/Delayed-chronic-intracranial-subdural-hematomacomplicating-resection-of-a-tanycytic-thoracic-ependymoma/ 
reported only 1 time to our knowledge. ${ }^{[1]}$ We report a case of delayed chronic subdural hematoma following resection of a thoracic tumor that adds to this small collection and illustrates the need for a high degree of suspicion for this condition in patients, who present with symptoms of intracranial hypotension days or even weeks following spinal tumor resection.

\section{CASE DESCRIPTION}

A 57-year-old woman presented with a 1-year history of progressive paraparesis. She reported pain radiating to both legs for several years and had been unable to walk for the previous 3 months. Her examination confirmed a severe paraparesis and a T12 sensory level but no bowel of bladder deficits.

A magnetic resonance (MR) scan revealed an enhancing tumor on the right side of the thoracic spine at the Tl1-T12 level [Figures la, b and 2a, b]. A right extended T12 laminectomy was performed to expose a large dumbbell tumor located in the intradural and extramedullary space. The tumor was dissected from the spinal cord and completely removed using standard microsurgical techniques. Following a short thoracic pedicle fixation T10-T11-T12 [Figure 3a], dural closure was achieved with 4-0 and 5-0 silk, Gelfoam, and fibrin glue. A dural tear was not appreciated during the procedure.

Pathologic examination revealed a tanycytic ependymoma, described only rarely in this location. ${ }^{[4]}$

Postoperatively, she experienced a rapid and progressive recovery of lower extremity motor and sensory function. Her walking ability improved, and she was discharged 10 days later.

One month following her resection, the patient complained of a persistent headache and was found
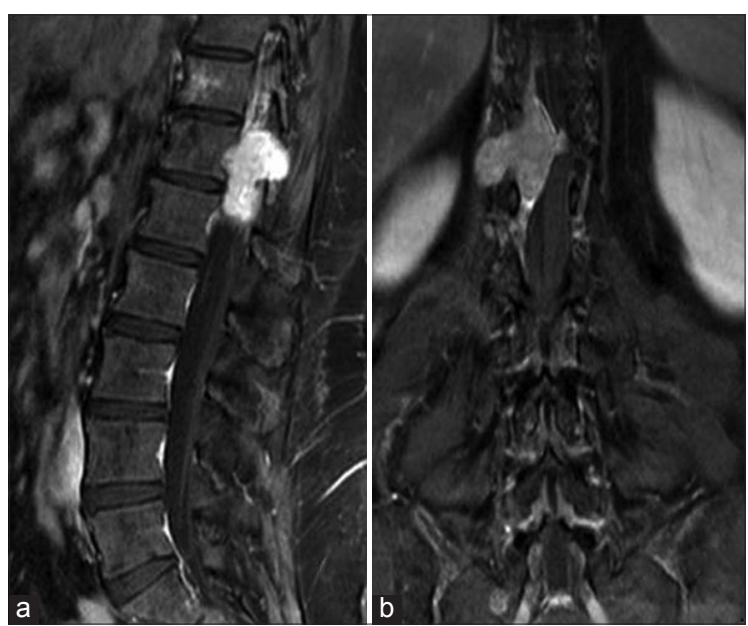

Figure I: Preoperative magnetic resonance images. TI-weighted gadolinium-enhanced (a) sagittal and (b) coronal showing the dumbbell shape of the tumor to have a mild right hemiparesis. The remainder of her neurologic examination was unremarkable.

She denied any history of recent or remote head trauma or alcohol abuse and had no detectable coagulopathy.

Her thoracic incision was well-healed without evidence of CSF leakage.

A computed tomography (CT) scan showed an $18 \mathrm{~mm}$ thick collection of hypodense fluid in the subdural space over the left frontoparietal region with an $8 \mathrm{~mm}$ midline shift [Figure 4a].

An MR imaging (MRI) of her thoracic spine showed a CSF collection at the resection site. She was felt that CSF leakage at the surgical site had produced intracranial hypotension and a chronic subdural hematoma that accounted for her symptoms and signs [Figure $3 \mathrm{~b}$ and $\mathrm{c}$ ].

The subdural space was evacuated through single burr hole, and a follow-up CT scan confirmed the resolution of the fluid and the midline shift [Figure 4b]. Her symptoms completely resolved, and she was discharged 2 weeks later with no neurological sequelae.

\section{DISCUSSION}

To the best of our knowledge, this is the second report of a chronic subdural hematoma occurring in a delayed fashion following resection of a thoracic spinal tumor ${ }^{[11]}$ A postresection MRI scan of our patient showed a CSF collection at the resection site, consonant with production of the subdural hematoma due to intracranial hypotension secondary to this occult CSF leak. Although CSF leaks were not detected in some of the previous reports, similar mechanisms were suggested.

Dural tears during neurosurgical procedures are common, with a prevalence of $1-17 \%{ }^{[6]}$ Furthermore, intracranial hypotension secondary to a CSF leak is a well-recognized mechanism for the production of a subdural hematoma. ${ }^{[1,9]}$ It is, therefore, not surprising that secondary intracranial
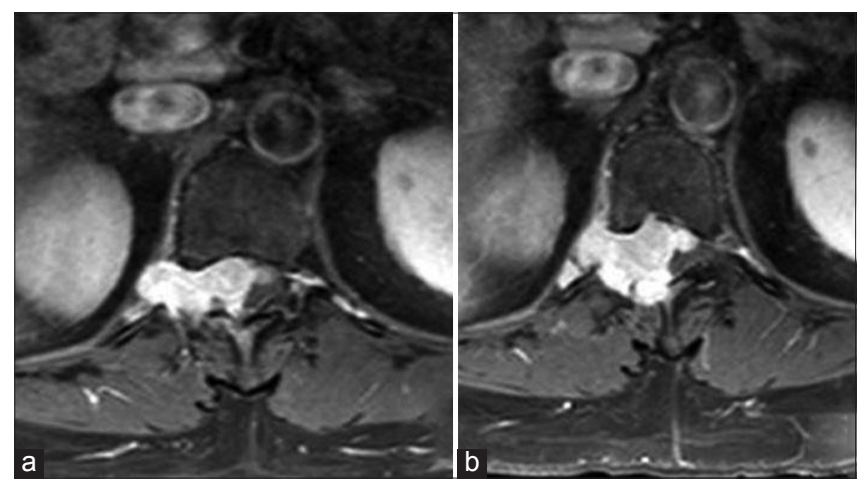

Figure 2: Preoperative magnetic resonance images (a and b) TI-weighted gadolinium-enhanced with axial reconstruction showing the massive enhancement of the intradural extramedullary tumor 

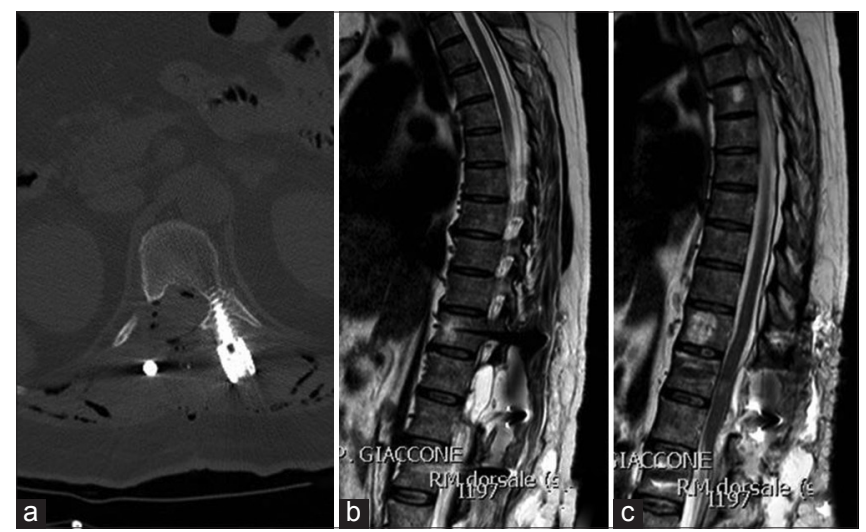

Figure 3: (a) Postoperative computed tomography bone window axial reconstruction showing ipsilateral laminectomy and contralateral pedicle screw. (b and c) Postoperative magnetic resonance $T 2$-weighted sagittal reconstructions showing cerebrospinal fluid collection and complete removal of the lesion

hematomas have been reported following myelography, lumbar puncture, spinal anesthesia, ventricular shunt procedures, placement of CSF drains, spine trauma, craniotomy, and spine surgery. ${ }^{[8,10]}$ Subsequent development of chronic subdural hematomas, however, occurs infrequently with an incidence of $0.3-1.5 \%{ }^{[8]}$ Furthermore, there are very few reports of intracranial subdural hematoma following spine surgery. Case reports include a patient undergoing a lumbar discectomy, ${ }^{[2]}$ a resection of a $\mathrm{T} 5$ metastatic lesion, ${ }^{[3]}$ a patient undergoing lumbar fusion, ${ }^{[7]}$ and two patients developing chronic subdural hematomas a few weeks after lumbar microdiscectomy. ${ }^{[2,6]}$

\section{CONCLUSION}

We report a very rare occurrence of a chronic intracranial subdural hematoma occurring in a delayed fashion after resection of a thoracic spinal tumor. The occurrence of this hematoma was likely due to intracranial hypotension due to CSF leakage, which may occur despite meticulous wound closure and the use of fibrin glue. The index of suspicion for an intracranial mass in patients presenting with a headache or other symptoms not explained by spinal pathology should be high, and acute diagnostic and therapeutic measures should be promptly instituted.

Financial support and sponsorship Nil.

\section{Conflicts of interest}

There are no conflicts of interest.

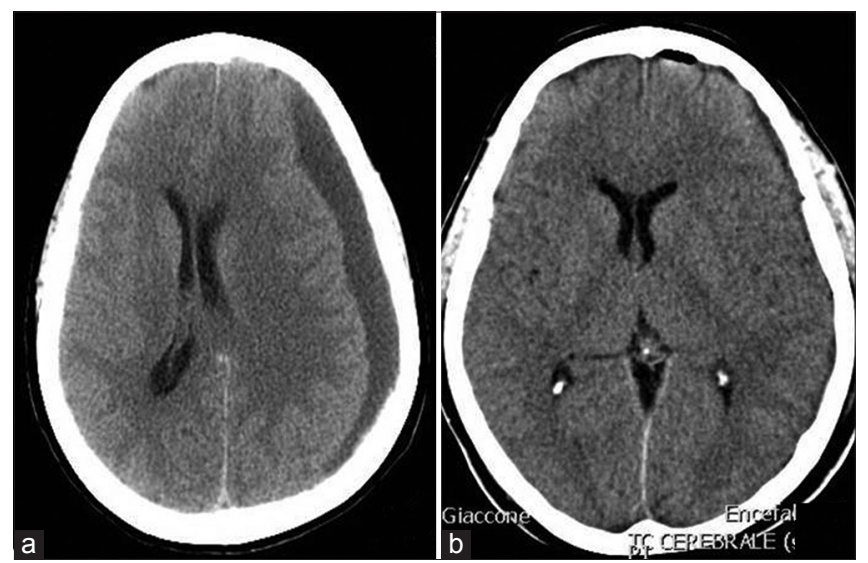

Figure 4: Head computed tomography scan showing an $18 \mathrm{~mm}$ thick frontoparietal left subdural hypodense fluid collection associated with mass effect and an $8 \mathrm{~mm}$ midline shift to the right (a) before and (b) after surgical evacuation

\section{REFERENCES}

I. Beck J, Gralla J, Fung C, Ulrich CT, Schucht P, Fichtner J, et al. Spinal cerebrospinal fluid leak as the cause of chronic subdural hematomas in nongeriatric patients. J Neurosurg 2014;121:1380-7.

2. Burkhard $P R$, Duff JM. Bilateral subdural hematomas following routine lumbar diskectomy. Headache 2000;40:480-2.

3. Hentschel SJ, Rhines LD, Wong FC, Gokaslan ZL, McCutcheon. Subarachnoid-pleural fistula after resection of thoracic tumors. J Neurosurg 2004 Apr; 100 (4 Suppl Spine):332-6.

4. Ishihama H, Nakamura M, Funao H, Ishii K, Matsumoto M, Toyama Y, et al. A rare case of spinal dumbbell tanycytic ependymoma. Spine (Phila Pa 1976) 20I I;36:E6I2-4.

5. Kristof RA, Grimm JM, Stoffel-Wagner B. Cerebrospinal fluid leakage into the subdural space: Possible influence on the pathogenesis and recurrence frequency of chronic subdural hematoma and subdural hygroma.J Neurosurg 2008; 108:275-80.

6. Kuhn J, Hofmann B, Knitelius HO, Coenen HH, Bewermeyer H. Bilateral subdural haematomata and lumbar pseudomeningocele due to a chronic leakage of liquor cerebrospinalis after a lumbar discectomy with the application of ADCON-L gel. J Neurol Neurosurg Psychiatry 2005;76:1031-3.

7. Lu CH, Ho ST, Kong SS, Cherng CH,Wong CS. Intracranial subdural hematoma after unintended durotomy during spine surgery. Can JAnaesth 2002;49: 100-2.

8. Mori K, Maeda M. Risk factors for the occurrence of chronic subdural haematomas after neurosurgical procedures. Acta Neurochir (Wien) 2003;145:533-39.

9. SchievinkWI, Maya MM, Pikul BK, Louy C. Spontaneous spinal cerebrospinal fluid leaks as the cause of subdural hematomas in elderly patients on anticoagulation.J Neurosurg 20 I0; I I2:295-9.

10. Sciubba DM, Kretzer RM, Wang PP. Acute intracranial subdural hematoma following a lumbar CSF leak caused by spine surgery. Spine (Phila Pa 1976) 2005;30:E730-2.

II. Watanabe A, Takai $\mathrm{H}$, Ogino S, Ohki T, Ohki I. Intracranial subdural hematoma after resection of a thoracic spinal cord tumor. J Spinal Disord Tech 2002;15:533-6. 